\title{
Um artista entre Europa e Novo Mundo: Joaquín Torres-García
}

\author{
An artist between Europe and the New World: \\ Joaquín Torres-García
}

Maria Lúcia Bastos Kern*

Resumo: Este ensaio tem por objetivo analisar a trajetória do artista Joaquín Torres-García (1874-1949), suas narrativas, memórias e pinturas feitas entre o Velho e o Novo Mundo. As narrativas são enfocadas a partir dos livros Historia de mi vida (1939) e La ciudad sin nombre (1941) e dos trabalhos executados por ele durante a viagem e na chegada em Montevidéu. O ensaio apresenta uma reflexão sobre os deslocamentos, as experiências artísticas e pessoais e as intenções de seus livros.

Palavras-chave: Arte. Modernidade. Cidades.

Abstract: This essay aims to analyze the trajectory of the artist Joaquín TorresGarcía (1874-1949), his narratives, memoirs and paintings made between the Old and New World. The narratives are focused from the books Historia de mi vida (1939) and La ciudad sin nombre (1941) and the works executed by him during the trip and upon arrival in Montevideo. The essay presents a reflection on the displacements, the artistic and personal experiences and intentions of his books.

Keywords: Art. Modernity. Cities.

* Professora do Programa de Pós-Graduação em História da PUCRS e Pesquisadora do CNPq. 


\section{Introdução}

Torres-García viajou entre o Velho e o Novo Mundo e narrou em livros os percursos realizados, as observações sobre os locais conhecidos e refletiu a respeito das diversidades encontradas. Apesar de seus recorrentes deslocamentos e textos escritos, a sua trajetória não se insere na categoria tradicional de artista viajante que participou de expedições científicas e impulsionou as práticas artísticas naturalistas. Em suas narrativas a descrição das singularidades da natureza não foi o seu enfoque principal. Os seus desenhos e suas pinturas também não evidenciam a intenção de informar e ilustrar o conhecimento científico como fizeram os artistas naturalistas.

Nos livros publicados, Torres-García relatou a sua trajetória, as experiências vivenciadas, os estranhamentos, as pesquisas, as criações poéticas e as reflexões sobre as diferentes práticas e concepções artísticas.

Ele se integra na categoria de artista moderno de vanguarda que aspirou revolucionar os sentidos de arte e de mundo, enfrentou a necessidade de criação da obra autônoma, independente da literatura e das representações naturalistas, com objetivo de elaborar novos meios expressivos. As viagens possibilitaram o contato com o desconhecido e distintas percepções de mundo que colaboraram nos seus processos de experimentação.

Consciente de seu papel como agente social e de sua liberdade, Torres-García fez investigações e vivenciou um processo conflituoso e solitário, para transgredir o convencional, criar poéticas e submetê-las à sociedade, como portadoras de verdade e de conteúdo universal. A sua obra e as suas narrativas foram concebidas como conhecimento e testemunho das etapas de pesquisa.

Nos seus textos, Torres-García analisou as mudanças e os percursos efetuados, os próprios questionamentos, bem como os projetos plásticos com propósitos éticos. Ele vivenciou as permanentes crises do mundo moderno e como artista da modernidade planejou o futuro ao acreditar que a arte tinha a potencialidade de transformá-lo e repor a ordem (Kern, 2012, p. 67).

Apesar de sua atuação na liderança de movimentos de vanguarda, de procurar estar à frente de seu tempo e de militância em prol de suas convicções, Torres-García, como o tradicional artista viajante descreveu os percursos, verificou as particularidades das cidades em que viveu e ilustrou os textos com imagens das mesmas. 
O presente ensaio tem em vista analisar as narrativas desse artista a partir dos livros História de mi vida (1939) e La ciudad sin nombre (1941) e das obras por ele efetuadas, durante a viagem entre o Velho e o Novo Mundo, e após a sua chegada em Montevidéu. Procura ainda refletir a respeito de seus deslocamentos, suas experiências pessoais e plásticas e desvendar as intenções de suas narrativas.

\section{Trajetória do artista}

Uruguaio de nascimento (1874-1949), porém com uma vivência europeia de 43 anos. No velho continente, ele conseguiu desenvolver a sua formação artística, intelectual e profissional. Inicialmente, residiu em Barcelona (1891-1920), onde liderou movimentos artísticos, publicou artigos e livros, expôs e fez conferências. Viajou pelo continente para conhecer a arte e dar continuidade à sua formação. Apesar de sua integração no campo artístico e intelectual estava insatisfeito com os rumos da política na Catalunha, e decidiu viver em Nova Iorque (1920-22), motivado pelo "desejo de ver uma grande cidade moderna" (Torres-Garcia, 1990, p. 144) e mecanizada. Acreditava que esta poderia oferecer melhores condições para implantar a indústria de brinquedos, cujo projeto fracassara em Barcelona. Torres-García pensou também que nessa cidade avançada em termos técnicos, arquitetônicos e urbanísticos teria maiores oportunidades, como artista moderno.

Ao chegar a Nova Iorque, se deslumbrou: "Que vida! Que movimento! tudo é mecânico, ordenado, limpo (...)! Esta é a civilização (...) Oh, que velha e triste é a Europa! Lá se encontra toda aquela gente meio corroída com suas misérias" (Torres-Garcia, 1990, p.151). Em cartas e livro, o artista expressou a sua euforia em relação à cidade norteamericana, símbolo de progresso e de futuro, em face à crise que vivia a Europa do pós-guerra. No entanto, o deslumbramento inicial cedeu lugar ao desânimo, porque seus projetos não foram bem sucedidos.

Em 1922, ele começou o caderno de desenhos coloridos, "Goodbye New York", no qual a cidade moderna lhe permitiu criar novas formas plásticas, como havia efetuado em Barcelona (1917-20). Esse caderno representou a sua decisão de voltar para a Europa, medida resultante, em parte, da tentativa fracassada de industrializar os brinquedos em madeira policromada. Torres-García constatou ainda que o ambiente artístico nova-iorquino não era o que projetara, pois teria que renunciar a si mesmo, num momento em que acreditava que deveria manter a sua identidade pessoal, como artista. As experiências que teve nesta 
cidade foram no sentido de direcionamento de seu trabalho, o que lhe desagradou muito (Torres-Garcia, 1990, p. 170). O artista evidenciou também em textos o seu choque e estranhamento face à excessiva racionalização da sociedade norte-americana. Apesar de seu desejo de ser moderno, ele sentiu profundamente a adversidade de valores.

Neste momento de pessimismo, ele declarou que a moderna cidade de Nova Iorque, ao mesmo tempo, que o atraiu, o repeliu. Ir embora representou sua libertação, apesar de deixar uma "civilização materialista acabadíssima" (Torres-Garcia, 1990, p. 170-172). A primazia de valores materiais sobre os espirituais assustaram Torres-García, levando-o a buscar a alma e o espírito na Europa, valores oriundos da velha tradição humanista, que não encontrou na América do Norte.

Após um período na Itália, onde passou temporada em Fiesole e Livorno, na Toscana, ele se dirigiu com a família para França, fixando-se em Paris (1926-32). Nesta cidade, a sua obra sofreu um grande processo de mudança, que se formalizou num Construtivismo próprio, fato que lhe permitiu fazer várias exposições e liderar o grupo e a revista Cercle et Carré (1930-31), formados por artistas de vanguarda como Piet Mondrian, Luigi Russolo, Wassily Kandisnky, Anton Pevsner, dentre outros. Escreveu pequenos livros, nos quais expôs o seu pensamento a respeito de suas experimentações plásticas. Com a crise econômica causada pelo craque da bolsa de Nova Iorque, Torres-García foi residir em Madri, onde tinha amigos e esperança de conseguir trabalho para poder manter a sua família. Não tendo sucesso nessa cidade, começou a preparar a volta ao Uruguai. ${ }^{1}$

\section{Retorno: as narrativas, as observações e a obra}

Durante a viagem da Europa para a América, ele escreveu o livro História de mi vida, publicado em Montevidéu (1939). Neste, o artista narrou a sua trajetória, os 43 anos vividos na Europa e nos EUA, os inúmeros projetos fracassados e as dificuldades materiais enfrentadas, no entre - guerras, que o condicionaram a viajar sempre em busca de melhores condições profissionais e de vida. Destacou as tentativas mal sucedidas de retorno ao Uruguai, junto ao governo, antes de viajar para Nova Iorque (1920), deixando claro que essa possibilidade seria a sua

1 Em Madri, fundou o Grupo de Arte Constructivo, fez conferências e exposições, podendose destacar a mostra no Museu de Arte Moderna. O contato com artistas e intelectuais espanhóis foi mantido, no Uruguai, através de correspondência, de textos e obras trocadas. 
última opção. Provavelmente, pela constatação de que em Montevidéu o ambiente artístico era ainda muito limitado para as suas ambições profissionais. Antes, projetou sem sucesso residir em Paris e Bruxelas, mas ao perceber a estagnação do mercado de arte e a crise gerada pela primeira guerra, principalmente, na capital belga, ele acabou desistindo.

O texto desse livro revela as suas reflexões sobre os planos que o conduziram a recorrentes mudanças de cidades e os problemas vivenciados, seus questionamentos e pesquisas. $\mathrm{O}$ artista utilizou a terceira pessoa ou o próprio nome para referir-se a si mesmo, e exprimiu as suas angústias, na busca de justificativas a respeito de sua trajetória, de seus deslocamentos e de sua integração ou desavença com intelectuais e artistas.

Em História de mi vida, relatou ainda os importantes momentos, desde a sua formação, suas práticas artísticas, exposições e obras realizadas, até os movimentos liderados e as suas relações com os grandes artistas de vanguarda. Nessas ocasiões em que descreveu os movimentos culturais, principalmente, em Barcelona e Paris, o autor evidenciou a necessidade de demonstrar a sua autoridade no campo da arte moderna com vistas à própria legitimação junto à sociedade uruguaia, que desconhecia a sua obra. O autor, cujo livro foi concluído no seu país, buscou o seu reconhecimento diante das dificuldades e resistências experimentadas, após o retorno, e de suas intransigências em relação a outras práticas e concepções artísticas.

Torres-García, ao longo de sua vida, escreveu e publicou inúmeros artigos e livros, em que divulgou e explicou suas concepções. Muitos desses textos eram permeados por discursos persuasivos e dogmáticos, enquanto em outros se verifica que tinham a finalidade do autor pensar a própria obra e as questões filosóficas e espirituais com as quais elas se vinculavam.

O discurso de autonomia da arte moderna e o abandono da representação do mundo visível estimularam o artista a se dedicar à expressão escrita aliada à imagem, como estratégia para exprimir o pensamento e trazer a palavra para o interior da obra. Os símbolos são inseridos nos textos de Torres-García como meios de visualização, expressão e reforço das ideias, bem como de plasticidade. Na pintura, eles exercem papéis semelhantes porque ela se desvincula de sua função referencial em prol da pureza das formas e da criação de linguagem própria. O texto é, assim, uma modalidade de estruturar as suas ideias teóricas, criar conceitos e ordená-los, num momento em que o artista 
continua a investigação. É ainda uma das estratégias utilizadas para divulgar a sua obra, pouco conhecida do público uruguaio.

Ele saiu de Montevidéu, ainda jovem, em 1891, e quando retornou em 1934, mostrou-se surpreendido com a descoberta de sua cidade e definiu a estética que seria pertinente à mesma. Nas suas narrativas, Torres-García a descreveu como detentora de um caráter único que a tornou inconfundível: casas baixas e ruas largas que permitiam a abundância de luz e o maior alcance visual do espaço urbano, diferente de Nova Iorque com seus arranha-céus. Depois desse longo período na Europa, a luz lhe pareceu branca e luminosa. Diante de tais singularidades, declarou que a arte dessa cidade deveria ser construída de forma "planista e bidimensional, esquemática e sintética; arte de grandes ritmos e estreitamente ligada à arquitetura" (Torres-García, 1996. p. 47). Esta descrição formal era a que ele praticava no momento e a que gostaria que fosse seguida pelos uruguaios. As suas ações eram direcionadas a formar discípulos e evidenciam as estratégias programadas para tal fim.

A pintura passou também por um processo de transformação. As cores primárias tornaram-se mais usuais, contrastantes, planas e o sol, símbolo da bandeira nacional e de divindade nas culturas pré-colombianas, é representado de forma recorrente, em geral no plano superior e em destaque. As representações fragmentadas da arquitetura e ordenadas do espaço urbano são freqüentes em suas pinturas.

A concepção de cidade mais humana, pensada na última etapa de sua estadia na Europa, foi a que ele defendeu no livro La ciudad sin nombre (1941), escrito em Montevidéu e tendo a mesma como cenário. Apesar do título, o próprio artista a identificou no final do livro e, ao longo do mesmo, inseriu desenhos de edifícios e monumentos emblemáticos dessa cidade que permitem ao leitor rapidamente reconhecê-la.

La ciudad sin nombre foi escrito e desenhado pelo próprio artista, que mesclou texto e representações visuais do espaço urbano e da arquitetura, de forma a um complementar o outro. A narrativa foi construída de modo distinto do livro anterior, pois Torres-García se referiu a si mesmo utilizando o eu e fazendo menção ao Monumento Cósmico por ele criado e aos seus conceitos de arte.

Ele construiu uma narrativa em que misturou a ficção e o real, assim como contrastou a cidade moderna, Nova Iorque, com a capital do Uruguai. O personagem da ficção, que ora é o próprio autor, translada 
pelas duas cidades, comoflaneur, revela a sua percepção das edificações, avenidas, dos portos, da publicidade e da homogeneidade dos espaços urbanos modernos, em detrimento das singularidades dos daqueles que conservam as tradições.

O olhar aguçado e as reflexões que são realizadas permitiram ao artista viajante, desde Barcelona, passando por Nova Iorque, Paris, Madri e Montevidéu elaborar a sua linguagem plástica a partir de signos modernos e típicos de cada cidade, quase sempre salientando a velocidade, a mecanização e a multidão. A partir de Paris, as suas pinturas foram perdendo a noção do dinamismo moderno em prol da estabilidade e ausência de movimento. Os símbolos das recorrentes viagens e deslocamentos foram também integrados na sua obra, tais como: portos, navios, âncoras, bússolas, trens dentre outros. Eles se constituíram como traços de memória e compuseram a sua poética, integrados à estrutura geométrica ortogonal, de origem clássica.

Torres-García, ao descrever o espaço urbano e estabelecer paralelos com a sua visão de arte, apresentou a configuração do mesmo a partir da plasticidade que teria lhe despertado. Apesar de valorizar o moderno, via na cidade tradicional a beleza, as particularidades e a identidade dos antigos bairros. As cidades modernas eram percebidas pelo artista pela ausência caráter próprio, uniformizadas pelo comércio com as propagandas, os mesmos tipos de lojas e de vitrines.

Os relatos e as evidências negativas a respeito da modernidade expressam a alteridade do artista com vivência europeia, em confronto com o mundo nova-iorquino. Os arranha-céus, as avenidas, a mecanização e a excessiva racionalização modernas são fenômenos que, mesmo após vinte anos, continuam chocando o artista.

Em La ciudad sin nombre Torres-García não só analisou os espaços tradicionais e modernos da capital uruguaia, mas também estabeleceu o contraponto com a produção plástica conservadora, que o condicionou a explicar as razões de ter voltado ao país: "levantar a arte, criar uma nova com ciência, buscar a tradição profunda" (Torres-García, 1941, s.p.). Os argumentos eram de fato pouco convincentes, mas compõem as inúmeras declarações contrárias à arte local, dentre as quais a afirmação de que "a pintura era bem medíocre" (Torres-García, 1941, s.p.).

Logo após a sua chegada a Montevidéu, ele procurou dinamizar o campo de arte local e conduzir o movimento de renovação estética e institucional, num momento em que a arte uruguaia estava configurada nas representações nacionais, no Realismo Social e em obras de caráter 
essencialmente formalistas. ${ }^{2}$ Torres-García enfrentou, assim, distintas concepções artísticas e se mostrou intransigente em relação às mesmas, visto que tinha a ambição de exercer a liderança e formar discípulos a partir de teorias de sua arte o Universalismo Constructivo. A denominação foi dada quando começou a viver em Montevidéu e intensificou a pesquisa nas culturas pré-colombianas, na busca de criação de uma arte para toda a América, em oposição às excessivas representações nacionais dominantes. Ele não as aceitava, pois vivenciou, na Europa, os nacionalismos exacerbados e as perseguições políticas sofridas pelos artistas modernos.

Com a meta de mudar o cenário artístico do país e do continente, ele assumiu um papel quase messiânico para difundir as suas ideias e os novos conceitos de arte através de inumeráveis conferências, cursos, publicações e da criação da Asociación de Arte Constructivo (19351939), do Taller Torres-García (1944) e das revistas Removedor (19451951) e Circulo y Cuadrado (1936). Esta última revista, de caráter internacional, constituiu-se como $2^{\mathrm{a}}$. edição de Cercle et Carré e veículo de propagação de suas teorias e dos movimentos modernos europeus com os quais ele se identificava. Os seus livros e a revista tinham circulação na América Latina, Europa e EUA. ${ }^{3}$ Ele mantinha uma coluna no jornal La Nación, em Buenos Aires, onde ministrou palestras, fez exposições e publicou o livro Universalismo Constructivo (1944). ${ }^{4}$ Essas iniciativas foram importantes porque permitiram aos artistas sul-americanos conhecerem a arte moderna europeia, no momento de eclosão da $2^{\text {a }}$ Guerra Mundial, em que o contato com Velho Mundo se tornara difícil.

O Taller Torres-García foi de tal forma bem sucedido na formação de artistas uruguaios, argentinos e espanhóis, na promoção de exposições e na realização de obras conjuntas (murais), que repercutiu entre artistas e críticos de arte latino-americanos, espanhóis e norte-americanos. As suas atividades de ensino e de difusão do Universalismo Constructivo

2 Nos anos de 1930, as crises política e econômica internacionais e os nacionalismos exacerbados propagaram-se no país e nas artes, sobretudo, em 1933, quando, no Uruguai, ocorreu o golpe de estado.

3 As principais instituições em que circula a revista: Biblioteca do Congresso e Galeria Nacional de Arte em Washington, Moholy-Nagy Instituto de Desenho em Chicago, Artistas Americanos Abstratos, Galeria de Arte Viva e associada do Museu Guggenheim, em Nova Iorque. No Brasil, a revista tem intercâmbio com a Gazeta de Arte e constata-se o provável conhecimento das suas ideias antes da I Bienal de São Paulo. DUNCAN, B. 1974 , p. 40

4 Ele expõe em Buenos Aires (1942, 1944, 1949 e 1951). 
no Taller fazem do mesmo uma entidade sem fronteiras ao congregar artistas, arquitetos e críticos de arte estrangeiros, num local de visitação para conhecer o trabalho desenvolvido.

As estratégias traçadas por Torres-García para propagar suas ideias e obra possibilitaram que o mesmo liderasse o início do movimento de arte concreta, em Buenos Aires, e que fosse convidado a fazer exposições em grandes centros europeus e norte-americanos. As suas obras e reflexões tornaram-se, assim, conhecidas fora do Uruguai e estimularam vários estudos monográficos, sendo os mesmos publicados em vida, na Argentina, no Chile e no seu país. ${ }^{5}$

Torres-García absorveu na Europa as tradicionais e as novas concepções e práticas artísticas, as reelaborou ao resgatar as raízes culturais latino-americanas e signos primitivos e místicos, criando os próprios conceitos de arte e poéticas. Fez projeções utópicas de ordem cultural e espiritual para a América Latina, cujas ideias permearam também as suas obras, num momento de crise do materialismo e de crença na possibilidade de surgimento de um novo homem e de unidade dos povos. Ele planificou a arte integrada à vida cotidiana, como fora nas culturas pré-colombianas, em que todo o homem poderia ser um artista.

Depois de tantos deslocamentos e viagens, ele se fixou em Montevidéu, onde assumiu o papel de liderança das transformações das artes, dando projeção internacional às mesmas. Após a sua morte, seus discípulos mantiveram o Taller e as práticas por ele ensinadas. As obras e o pensamento desse artista despertam ainda na atualidade interesse e suscitam debates, sendo objetos de importantes exposições retrospectivas e utilizadas como fundamentos de curadorias, que têm em vista pensar a modernidade estética. As suas obras e os seus livros continuam viajando pelo mundo e sendo publicados em novas edições.

Observa-se que através de suas narrativas e memórias, TorresGarcía refletiu a respeito dos percursos efetuados ao longo de sua vida e obra, bem como planificou estratégias para institucionalizá-la e disseminá-la entre o Velho e o Novo Mundo. Ele expressou seus estranhamentos, as adversidades vivenciadas e constatou as diferenças culturais e artísticas, propiciadas pelas viagens. Estas alteraram o artista como indivíduo, o seu olhar sobre si mesmo e o mundo que o rodeou. Ao se distanciar de seu país e vivenciar as recorrentes crises do mundo

5 Em 1941, Alfredo Cáceres publica uma monografia sobre Torres-García em Montevidéu; Claude Schaefer em Buenos Aires; e no Chile, o poeta Vicente Huidobro "Homenaje a Torres-García”. O livro Universalismo Constructivo (2 volumes) exerce grande interesse entre artistas latino-americanos e espanhóis. 
moderno, em grandes centros cosmopolitas, teve oportunidade de lançar um olhar mais arguto e diferenciado que permitiu procurar através da arte projetar novos sentidos e soluções.

\section{Referências}

KERN, Maria Lúcia B. Joaquín Torres-García: a arte como lugar da utopia e do mito. In: Torres-García: geometria, criação re proporção. Porto Alegre: Fundação Iberê Camargo, 2011.

TORRES-GARCÍA, J. La escuela del Sur. Lección 20. In: Universalismo constructivo y la escuela del Sur. Washington: Museo de Arte de las Américas, 1996.

TORRES-GARCIA, J. História de mi vida. Barcelona: Paidós, 1990.

TORRES-GARCÍA, J. La ciudad sin nombre. Montevidéu, 1941.

Solicitado em 17/09/2012

Aprovado em 18/10/2012 